\title{
Curcumin induces apoptosis and inhibits the growth of adrenocortical carcinoma: Identification of potential candidate genes and pathways by transcriptome analysis
}

\author{
XUEMEI HUANG ${ }^{1}$, CHUNFENG LIANG ${ }^{2}$, HAIYAN YANG ${ }^{2}$, XIN LI $^{2}$, XIUJUN DENG $^{2}$, XINGHUAN LIANG ${ }^{2}$, \\ $\mathrm{LI} \mathrm{LI}^{2}, \mathrm{ZHENXING} \mathrm{HUANG}^{2}$, DECHENG LU ${ }^{2}, \mathrm{YAN} \mathrm{MA}^{3 *}$ and ZUOJIE LUO ${ }^{2 *}$ \\ ${ }^{1}$ Department of Endocrinology, The Fifth Affiliated Hospital of Guangxi Medical University, Nanning, \\ Guangxi Zhuang Autonomous Region 530022; Departments of ${ }^{2}$ Endocrinology and ${ }^{3}$ Ultrasonic Diagnosis, \\ The First Affiliated Hospital of Guangxi Medical University, Nanning, \\ Guangxi Zhuang Autonomous Region 530021, P.R. China
}

Received September 17, 2020; Accepted March 19, 2021

DOI: 10.3892/ol.2021.12737

\begin{abstract}
Adrenocortical carcinoma (ACC) is an endocrine tumour with high malignancy, high invasiveness and poor prognosis. Curcumin, a major component in turmeric, has been reported to have good efficacy and biological safety in treating cancer. However, the role and mechanism of curcumin in ACC have not yet been fully investigated and were thus the focus of this study. In vitro, ACC SW-13 and NCI-H295R cells were treated with curcumin and their viability, migration and invasion were assessed by CCK- 8 and Transwell assays. Apoptosis was detected via flow cytometry and western blotting. High-throughput sequencing and comprehensive bioinformatics analyses were performed to elucidate the molecular processes underlying curcumin activity. In vivo, SW-13 cells were injected into nude mice, and the tumour volumes and weights were observed after 2 weeks
\end{abstract}

Correspondence to: Professor Zuojie Luo, Department of Endocrinology, The First Affiliated Hospital of Guangxi Medical University, 6 Shuangyong Road, Nanning, Guangxi Zhuang Autonomous Region 530021, P.R. China

E-mail: luozuojie@gxmu.edu.cn

Professor Yan Ma, Department of Ultrasonic Diagnosis, The First Affiliated Hospital of Guangxi Medical University, 6 Shuangyong Road, Nanning, Guangxi Zhuang Autonomous Region 530021, P.R. China

E-mail: luoma628@163.com

${ }^{*}$ Contributed equally

Abbreviations: ACC, adrenocortical carcinoma; DEGs, differentially expressed genes; GO, Gene Ontology; KEGG, Kyoto Encyclopedia of Genes and Genomes; PPI, protein-protein interaction; shRNA, short hairpin RNA; ER, endoplasmic reticulum; HSP70, heat shock protein 70

Key words: curcumin, ACC, high-throughput sequencing, transcriptome analysis, apoptosis of curcumin treatment. Organelle changes were observed by electron microscopy, and potential candidate genes and pathways were analysed by RT-qPCR and western blotting. The role of the $\mathrm{C} / \mathrm{EBP}$ homologous protein (CHOP) target gene in curcumin-induced ACC cell apoptosis was verified via lentiviral transfection experiments. Curcumin inhibited the viability, migration and invasion, and induced the apoptosis of ACC cells. Transcriptome sequencing analysis showed that curcumin treatment markedly changed the gene expression levels. Gene Ontology and Kyoto Encyclopedia of Genes and Genomes pathway enrichment analyses showed that the MAPK and endoplasmic reticulum (ER) stress pathways were the predominant pathways associated with curcumin-induced apoptosis of ACC cells. Subsequent in vivo and in vitro results demonstrated that the JNK, p38 MAPK and ER stress pathways were activated in curcumin-treated ACC cells, and that $\mathrm{CHOP}$ induction was responsible for curcumin-induced apoptosis of ACC cells. In summary, curcumin induced ACC cell apoptosis and inhibited tumour growth by activating the JNK, p38 MAPK and ER stress pathways. Thus, curcumin may be a potential therapeutic drug for ACC.

\section{Introduction}

Adrenocortical carcinoma (ACC) is an endocrine tumour with high malignancy, invasiveness and recurrence rate, and has a poor prognosis (1). The majority of patients are diagnosed at an advanced stage with invasion of adjacent organs or metastatic disease (2). Currently, complete resection is the only feasible method to treat ACC. However, the prognosis of patients with relapsed or metastatic disease is unfavourable as patients with metastatic ACC have an overall 5-year survival rate of $<20 \%$ (3). Chemotherapy remains an effective method of adjuvant therapy in patients with a high risk of relapse and metastasis, and mitotane is the only drug approved for the systemic treatment of ACC (4). However, mitotane has a narrow therapeutic range, poor bioavailability and side effects (5). Long-term treatment causes obvious adverse toxic effects, such as adrenal insufficiency, sexual dysfunction, 
hypothyroidism and neurotoxicity (6-8). Moreover, mitotane cannot improve long-term survival rates for patients with metastatic ACC or inoperable ACC, although it may delay tumour progression (9). Therefore, safe treatment strategies to overcome drug tolerance and minimize side effects are needed to improve ACC treatment.

Curcumin is a plant polyphenolic compound and a major component in turmeric (Curcuma longa) (10). Curcumin has been reported to have good efficacy and biological safety for treating cancer, with targeted inhibitory effects on gastric, colorectal, breast and cervical cancer (11-14). Curcumin induces the apoptosis of colon cancer cells with wild-type p53 and mutant p53 in a dose- and time-dependent manner (15). In addition, curcumin inhibits the nuclear translocation of $\mathrm{NF}-\kappa \mathrm{B}$ through the inhibition of I $\mathrm{B}$ kinase, leading to apoptosis of prostate carcinoma cells (16) and inducing apoptosis associated with endoplasmic reticulum (ER) stress in lung cancer cells (17). Moreover, curcumin induces cytotoxic effects in papillary thyroid cancer and cancer stem-like cells by targeting the JAK/STAT3 signalling pathway (18). In addition, clinical trials have indicated that curcumin is safe and exhibits therapeutic efficacy in patients with progressive, advanced types of cancer. A study by Sharma et al (19) indicated that curcumin extract may be administered safely for several months at daily doses of up to $2.2 \mathrm{~g}$ (equivalent to $180 \mathrm{mg}$ of curcumin), resulting in a clinical benefit in patients with advanced colorectal cancer. Curcumin also has anticancer activity and is tolerated and safe in patients with breast and prostate cancer $(20,21)$. However, whether curcumin can induce apoptosis of ACC cells or inhibit tumour growth is unclear, and the possible mechanisms remain undefined.

The current study evaluated the effect of curcumin on ACC and analysed the underlying mechanisms by high-throughput sequencing. The systemic analysis of curcumin-induced whole-transcriptome alterations provided precise molecular targets and signalling pathways, contributing to the improved application of curcumin for ACC treatment.

\section{Materials and methods}

Cell culture and drugs. The human SW-13 cell line was purchased from the National Collection of Authenticated Cell Cultures, Chinese Academy of Sciences (cat. no. TCHu221). The human NCI-H295R cell line was purchased from American Type Culture Collection (cat. no. ATCC ${ }^{\circledR}$ CRL-2128 ${ }^{\mathrm{TM}}$ ). The cells were cultured in high glucose DMEM (Gibco; Thermo Fisher Scientific, Inc.) supplemented with 10\% FBS (Gibco; Thermo Fisher Scientific, Inc.) and 1\% penicillin-streptomycin solution (Beijing Solarbio Science \& Technology Co., Ltd.). Mycoplasma testing was routinely carried out to ensure that the cell lines were mycoplasma-free. Cells were cultured in an incubator containing $5 \% \mathrm{CO}_{2}$ at $37^{\circ} \mathrm{C}$. Curcumin was purchased from Sigma-Aldrich; Merck KGaA, dissolved in DMSO and then diluted in DMEM to the desired concentrations.

Cell viability assay. SW-13 and NCI-H295R cells were plated in 96 -well plates at a density of $5 \times 10^{3}$ cells/well. Cells were allowed to attach overnight. The following day, cells were treated with $0,10,20,30,40,50,60,80$ or $100 \mu \mathrm{M}$ curcumin for 24 or $48 \mathrm{~h}$ at $37^{\circ} \mathrm{C}$. Cell viability was then measured with a Cell Counting Kit-8 (CCK-8) assay (Dojindo Molecular Technologies, Inc.). Briefly, CCK-8 solution (10 $\mu \mathrm{l})$ was added to each well and incubated for an additional $1 \mathrm{~h}$ at $37^{\circ} \mathrm{C}$, optical density values at $450 \mathrm{~nm}$ were assessed using a microplate reader (Fluoroskan Ascent ${ }^{\mathrm{TM}}$; Thermo Fisher Scientific, Inc.). The half-maximal inhibitory concentration $\left(\mathrm{IC}_{50}\right)$ values were calculated by SPSS v20.0 software (IBM Corp.)

Transwell migration and invasion assays. SW-13 and NCI-H295R cells were treated with $0,20,30$ or $40 \mu \mathrm{M}$ curcumin for $24 \mathrm{~h}$ at $37^{\circ} \mathrm{C}$. For the migration assay, $2 \times 10^{5}$ cells suspended in serum-free medium were seeded in the upper compartment of Transwell chambers (Corning, Inc.). Subsequently, $500 \mu \mathrm{l}$ medium containing $10 \%$ FBS was added to the lower compartment. For the invasion assay, the upper chambers were coated with Matrigel for $30 \mathrm{~min}$ at $37^{\circ} \mathrm{C}$ (Corning, Inc.). After incubation for $24 \mathrm{~h}$ at $37^{\circ} \mathrm{C}$ in $5 \% \mathrm{CO}_{2}$, the cells on the upper chambers were removed using a cotton swab, and the filters were washed with PBS. Cells that migrated to the bottom side of the membrane were fixed with $4 \%$ paraformaldehyde for $15 \mathrm{~min}$ at room temperature and stained with $0.1 \%$ crystal violet for $15 \mathrm{~min}$ at room temperature. Images were captured under a light microscope at a magnification of x100 (Nikon Corporation) and counted in five randomly selected visual fields using Image J software version 1.8.0 (National Institutes of Health).

Flow cytometry analyses of apoptosis. SW-13 and NCI-H295R cells were treated with $0,20,30$ or $40 \mu \mathrm{M}$ curcumin for $24 \mathrm{~h}$ at $37^{\circ} \mathrm{C}$. Cells were harvested and resuspended in binding buffer at a concentration of $1 \times 10^{6}$ cells $/ \mathrm{ml}$. Subsequently, $100 \mu \mathrm{l}$ cell suspension, $5 \mu \mathrm{l}$ Annexin V-APC and $5 \mu \mathrm{l}$ 7-AAD (BD Biosciences) solution were added to a culture tube and incubated for $15 \mathrm{~min}$ in the dark at room temperature. After $400 \mu \mathrm{l}$ binding buffer was added to each tube, apoptosis was analysed with a FACSCalibur ${ }^{\mathrm{TM}}$ flow cytometer (BD Biosciences). Data were analysed with FlowJo v10.5.3 software (FlowJo LLC).

RNA library preparation, high-throughput sequencing and RNA sequencing (RNA-seq) data analysis. Total RNA was extracted from control- and curcumin-treated groups of ACC SW-13 cells using TRIzol ${ }^{\circledR}$ (Takara Biotechnology Co., Ltd.). PCR amplification, product purification and quantification, and sequencing were carried out on the Illumina HiSeq platform at Sangon Biotech Co., Ltd. The RNA concentration was measured using a Qubit ${ }^{\circledR}$ RNA Assay kit (Life Technologies, Inc.) on a Qubit ${ }^{\circledR} 2.0$ fluorometer (Thermo Fisher Scientific, Inc.), and the RNA integrity was assessed using an RNA Nano 6000 Assay kit on the Bioanalyser 2100 system (both from Agilent Technologies, Inc.). A total of $2 \mu \mathrm{g}$ of RNA per sample was used as the input material, and mRNA was purified from total RNA using poly-T oligo-attached magnetic beads. Sequencing libraries were generated using the Hieff NGS $^{\text {TM }}$ MaxUp Dual-mode mRNA Library Prep Kit for Illumina ${ }^{\circledR}$ (Yeasen Biotech, Inc.) according to the manufacturer's protocol. PCR was performed with Phusion High-Fidelity DNA polymerase, Universal PCR primers and Index (X) Primer. Finally, the products were purified (AMPure XP 
Table I. Human primer sequences for reverse transcription-quantitative PCR.

\begin{tabular}{lll}
\hline Gene name & \multicolumn{1}{c}{ Forward primer, 5'-3' } & \multicolumn{1}{c}{ Reverse primer, 5'-3' } \\
\hline GAPDH & CAGGAGGCATTGCTGATGAT & GAAGGCTGGGGCTCATTT \\
HSP70 & AAGAACGCCCTGGAGTCCTACG & CTTGTCCGCCTCGCTGATCTTG \\
JNK & ACACCACAGAAATCCCTAGAAG & CACAGCATCTGATAGAGAAGGT \\
p38 & ATTTCAGTCCATCATTCATGCG & GTAAAAACGTCCAACAGACCAA \\
c-Jun & AAGATGGAAACGACCTTCTACG & CTTAGGGTTACTGTAGCCGTAG \\
c-Fos & CTTCCCAGAAGAGATGTCTGTG & TGGGAACAGGAAGTCATCAAAG \\
ATF4 & ATGGATTTGAAGGAGTTCGACT & AGAGATCACAAGTGTCATCCAA \\
CHOP & GAGAATGAAAGGAAAGTGGCAC & ATTCACCATTCGGTCAATCAGA \\
Bax & CGAACTGGACAGTAACATGGAG & CAGTTGCTGGCAAAGTAGAAA \\
Bcl-2 & TGCATCCCAAACAAGCTCCC & TGCCCTTGGTCTTCTGTGGA
\end{tabular}

HSP70, heat shock protein 70; ATF4, activating transcription factor 4; CHOP, C/EBP homologous protein.

Table II. Mouse primer sequences for reverse transcription-quantitative PCR.

\begin{tabular}{lll}
\hline Gene name & \multicolumn{1}{c}{ Forward primer, 5'-3' } & \multicolumn{1}{c}{ Reverse primer, 5'-3' } \\
\hline GAPDH & GGTTGTCTCCTGCGACTTCA & TGGTCCAGGGTTTCTTACTCC \\
HSP70 & CAACAAGATCACCATCACCAAC & TTCATGTTGAAGGCATAGGACT \\
JNK & TTGAAAACAGGCCTAAATACGC & GTTTGTTATGCTCTGAGTCAGC \\
p38 & AGGAATTCAATGACGTGTACCT & AGGTCCCTGTGAATTATGTCAG \\
c-Jun & GAAAGCTGTGTCCCCTGTCTG & CACACCATCTTCTGGTGTACAGT \\
c-Fos & TCTCTAGTGCCAACTTTATCCC & GAGATAGCTGCTCTACTTTGCC \\
ATF4 & AGTTTAGAGCTAGGCAGTGAAG & CATACAGATGCCACTGTCATTG \\
CHOP & CTCCAGATTCCAGTCAGAGTTC & ACTCTGTTTCCGTTTCCTAGTT \\
Bax & TTGCCCTCTTCTACTTTGCTAG & CCATGATGGTTCTGATCAGCTC \\
\hline
\end{tabular}

HSP70, heat shock protein 70; ATF4, activating transcription factor 4; CHOP, C/EBP homologous protein.

system), and the library quality was assessed on the Agilent Bioanalyser 2100 system. Paired-end sequencing of the library was performed on HiSeq XTen sequencers (Illumina, Inc.), and the quality of the sequencing data was evaluated with FastQC (version 0.11.2). The significant differentially expressed genes (DEGs) were determined using a of false discovery rate (FDR) corrected $\mathrm{P}$-value $<0.05$ and a fold change $>2$ as the threshold. Gene Ontology (GO) enrichment was performed with TopGO (version 2.24.0). Kyoto Encyclopedia of Genes and Genomes (KEGG) enrichment analysis was performed with ClusterProfiler (version 3.0.5), and a protein-protein interaction (PPI) network was constructed with the R igraph package and the STRING database (http://string-db.org).

Reverse transcription-quantitative $(R T-q) P C R$. After total RNA was extracted from ACC SW-13 cells, NCI-H295R cells and xenograft tumour tissues using TRIzol ${ }^{\circledR}$, and cDNA was synthesised using the Takara RT kit (Takara Biotechnology Co., Ltd.) at $37^{\circ} \mathrm{C}$ for $15 \mathrm{~min}, 85^{\circ} \mathrm{C}$ for $5 \mathrm{sec}$, and stored at $4^{\circ} \mathrm{C}$ until subsequent experimentation. Next, mRNA expression levels were measured via qPCR using SYBR ${ }^{\circledR}$-Green PCR Master Mix (Takara Biotechnology Co., Ltd.) in an Applied
Biosystems 7500 Real-Time PCR system (Thermo Fisher Scientific, Inc.). The thermocycling conditions were $95^{\circ} \mathrm{C}$ for $30 \mathrm{sec}$, followed by 40 cycles at $95^{\circ} \mathrm{C}$ for $5 \mathrm{sec}$ and $60^{\circ} \mathrm{C}$ for 34 sec. GAPDH was selected as the reference gene and expression levels were calculated according to the $2^{-\Delta \Delta \mathrm{Cq}}$ method (22). The primer sequences used are listed in Tables I and II.

Western blotting. Cells or tumour tissues were lysed with RIPA lysis buffer containing $1 \mathrm{mM}$ PMSF (Beijing Solarbio Science and Technology Co., Ltd.). Protein concentrations were determined with a BCA protein assay kit (Beyotime Institute of Biotechnology). A total of $50 \mu \mathrm{g}$ of total protein was separated using 10 or $12 \%$ SDS-PAGE and transferred to PVDF membranes (MilliporeSigma). Membranes were blocked with $5 \%$ non-fat milk for $1 \mathrm{~h}$ at room temperature. Subsequently, primary antibodies specific for JNK (cat. no. 9252), phosphorylated (p)-JNK (cat. no. 4668), p38 (cat. no. 9212), p-p38 (cat. no. 4511), c-Jun (cat. no. 9165), Bax (cat. no. 2772), Bcl-2 (cat. no. 3498) (all 1:1,000; Cell Signaling Technology, Inc.), heat shock protein 70 (HSP70; cat. no. 48597), c-Fos (cat. no. 49310), activating transcription factor 4 (ATF4; cat. no. 49174) and C/EBP homologous protein 
(CHOP; cat. no. 49418) (all 1:1,000; Signalway Antibody LLC) were added, and membranes were incubated overnight at $4^{\circ} \mathrm{C}$. After washing with $0.1 \%$ TBS-Tween-20, horseradish peroxidase-conjugated secondary antibodies (1:10,000; cat. no. L3012; Signalway Antibody LLC) were added for $1 \mathrm{~h}$ at room temperature. Protein bands were visualised using an Odyssey infrared laser scanner (LI-COR Biosciences) and analysed with ImageJ software v1.8.0 (National Institutes of Health). Membranes were also probed with an antibody specific for GAPDH (cat. no. 21612; 1:10,000; Signalway Antibody LLC), which was used as the loading control.

Lentiviral transfection. CHOP knockdown and negative control (GV493, scrambled sequence) lentiviruses were designed and synthesized by Shanghai GeneChem Co., Ltd. The selected targeting sequence of CHOP (CHOP shRNA) was CGAATGGTGAATCTGCACCAA, and the sequence of the negative control vector (NC) was TTCTCCGAACGTGTCACGT. SW-13 cells were plated into 12-well plates at a density of $1 \times 10^{5}$ cells/well and incubated overnight. Subsequently, the medium was replaced with medium containing lentivirus (CHOP shRNA or NC, $\mathrm{MOI}=50$ ). After $12 \mathrm{~h}$, the medium was replaced with DMEM supplemented with $10 \%$ FBS, and the expression of green fluorescent protein was observed using fluorescence microscopy at a magnification of $x 200$ (Nikon Corporation) after $72 \mathrm{~h}$. The cells were selected with $2 \mu \mathrm{g} / \mathrm{ml}$ puromycin (Beijing Solarbio Science \& Technology Co., Ltd.) for $24 \mathrm{~h}$ at $37^{\circ} \mathrm{C}$ to kill the non-transfected cells. Finally, the medium was replaced with complete medium. RT-qPCR and western blot analyses were performed to determine the efficiency of CHOP knockdown.

Xenograft transplantation and therapy. BALB/c nude male mice (4-week-old; $18-20 \mathrm{~g} ; \mathrm{n}=8$ ) were obtained from the Experimental Animal Center of Guangxi Medical University (Nanning, China) and raised under standard conditions (20-26 ${ }^{\circ} \mathrm{C}$ temperature; 40-60\% humidity; $12 \mathrm{~h}$ light/12 h dark cycle; food, drinking water and litter changed every 2 days) in the Experimental Animal Center of Guangxi Medical University (Nanning, China). All animal experiments were approved by the Animal Ethics and Welfare Committee of Guangxi Medical University. A total of $2 \times 10^{6}$ SW-13 cells in $100 \mu \mathrm{l}$ PBS per mouse were injected subcutaneously into the right flank. The tumours were measured every other day, and the tumour volumes were calculated with the following formula: Volume $=$ length $\mathrm{x}$ width ${ }^{2} \times 1 / 2$. When the tumour volumes were $100 \mathrm{~mm}^{3}$, the mice were randomly divided into three groups of eight mice per group. Curcumin dissolved in olive oil (50 or $100 \mathrm{mg} / \mathrm{kg}$ ) was administered via intraperitoneal injection to mice once daily for 2 weeks, while mice in the control group received injections of olive oil. At the end of treatment, the mice were anaesthetised with $1 \%$ sodium pentobarbital and then sacrificed using cervical dislocation. The tumours were removed and weighed for subsequent studies.

Electron microscopy. Tumour tissues were fixed with phosphate buffer ( $\mathrm{pH} 7.4$ ) containing $2.5 \%$ glutaraldehyde overnight at $4^{\circ} \mathrm{C}$. Tissues were then post-fixed with $1 \% \mathrm{OsO}_{4}$ for $1 \mathrm{~h}$ at room temperature, stained with $1 \%$ uranyl acetate for $1 \mathrm{~h}$ at room temperature, dehydrated through graded acetone solutions and embedded in Epon overnight at room temperature. Areas containing tissues were mounted in blocks and sliced into 70-nm-thick sections. Sections were examined under a transmission electron microscope (HT 7800; Hitachi Ltd.) at a magnification of $\mathrm{x} 2,500$ or $\mathrm{x} 7,000$.

Statistical analysis. Data are presented as the mean \pm SD and were analysed using SPSS v20.0 software (IBM Corp.). One-way ANOVA combined with Bonferroni's post-hoc test was employed to analyse the differences between sets of data. $\mathrm{P}<0.05$ was considered to indicate a statistically significant difference.

\section{Results}

Curcumin inhibits the viability, migration and invasion of ACC cells. The CCK-8 assay was used to evaluate the viability of SW-13 and NCI-H295R cells. SW-13 and NCI-H295R cells were exposed to various concentrations of curcumin $(0,10,20,30,40,50,60,80$ or $100 \mu \mathrm{M})$ for 24 or $48 \mathrm{~h}$. As shown in Fig. 1A, cell viability decreased significantly in a concentration-dependent manner. The $\mathrm{IC}_{50}$ values for curcumin in SW-13 and NCI-H295R cells were 50.809 \pm 1.706 and $59.271 \pm 1.773$ at $24 \mathrm{~h}$ and $35.917 \pm 1.555$ and $42.317 \pm 1.627$ at $48 \mathrm{~h}$, respectively (Table III). In the cell motility assay, both the migration and invasion of SW-13 and NCI-H295R cells were significantly decreased by exposure to curcumin for 24 h (Fig. 1B-E).

Curcumin induces apoptosis of ACC cells. To investigate the effects of curcumin on the apoptosis of SW-13 and NCI-H295R cells, flow cytometric analysis was performed using Annexin V-APC/7-AAD, revealing that curcumin induced apoptosis in a dose-dependent manner (Fig. 2A and B). Next, the expression levels of the apoptotic factor Bax and the anti-apoptotic factor Bcl-2 were examined by RT-qPCR and western blotting. As the concentration of curcumin increased, the mRNA and protein expression levels of the apoptotic factor Bax significantly increased, while those of the anti-apoptotic factor Bcl-2 significantly decreased (Fig. 2C and D). These results indicated that curcumin induced apoptosis in $\mathrm{ACC}$ cells.

RNA-seq and bioinformatic analyses of the mechanism of curcumin in ACC. The experimental conditions for transcriptome analysis were determined based on the aforementioned cell viability assays. The CCK-8 assay results showed that $50 \mu \mathrm{M}$ curcumin, which resulted in a cell viability of $49.9 \%$, was the closest to the $\mathrm{IC}_{50}$ of curcumin in SW-13 cells after incubation for $24 \mathrm{~h}$ (Fig. 1A). Therefore, transcriptome analysis was performed on SW-13 cells after treatment with $50 \mu \mathrm{M}$ curcumin for $24 \mathrm{~h}$. In total, 385 DEGs were identified in the curcumin-treated group compared with the control group; 114 genes were upregulated and 271 genes were downregulated (Fig. 3A). GO enrichment analysis was used to examine the processes in which the DEGs were involved, and the top ten enriched GO terms were associated with in 'cell cycle', 'cell proliferation', 'cell migration', 'cell differentiation' and 'execution phase of apoptosis' (Fig. 3B). KEGG enrichment analysis demonstrated that curcumin-induced apoptosis of ACC cells 


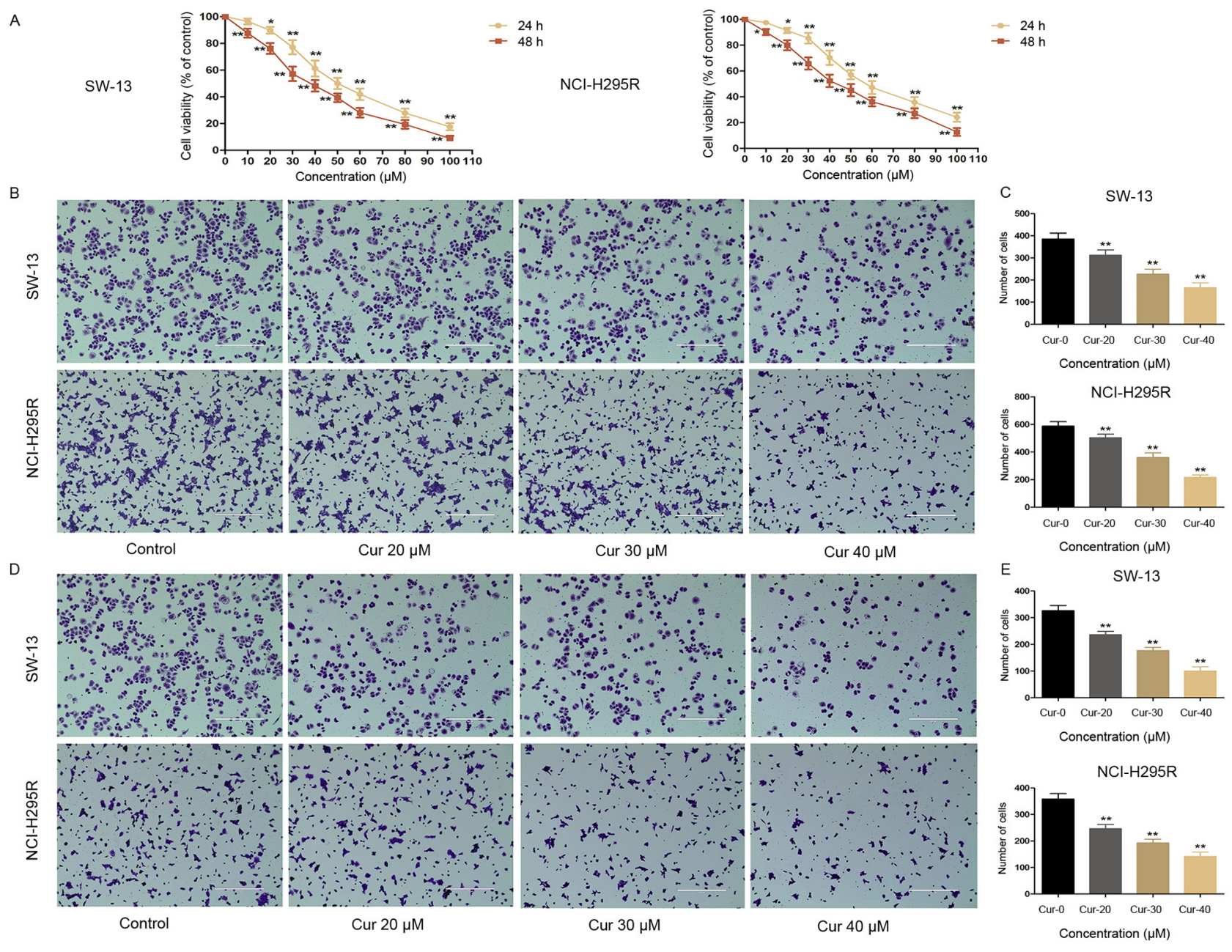

Figure 1. Curcumin inhibits the viability, migration and invasion of ACC cells. (A) Curcumin decreased SW-13 and NCI-H295R cell viability. (B) Curcumin inhibited SW-13 and NCI-H295R cell migration. Original magnification, x100. Scale bar, $400 \mu \mathrm{m}$. (C) Migrated cells were quantified. (D) Curcumin inhibited SW-13 and NCI-H295R cell invasion. Original magnification, $x 100$. Scale bar, $400 \mu \mathrm{m}$.(E) Invading cells were quantified. " $\mathrm{P}<0.05$ and ${ }^{* *} \mathrm{P}<0.01$ vs. Cur- 0 . Cur, curcumin.

Table III. $\mathrm{IC}_{50}$ values for curcumin in adrenocortical carcinoma cell lines.

Cell lines $\quad \mathrm{IC}_{50}$ at $24 \mathrm{~h} \pm \mathrm{SD}, \mu \mathrm{M} \quad \mathrm{IC}_{50}$ at $48 \mathrm{~h} \pm \mathrm{SD}, \mu \mathrm{M}$

\begin{tabular}{lll}
\hline SW-13 & $50.809 \pm 1.706$ & $35.917 \pm 1.555$ \\
NCI-H295R & $59.271 \pm 1.773$ & $42.317 \pm 1.627$
\end{tabular}

$\mathrm{IC}_{50}$, half-maximal inhibitory concentration.

was mediated primarily through the 'cell cycle', 'microRNAs in cancer', 'endoplasmic reticulum' and the 'MAPK signalling pathway' (Fig. 3C and D). These altered genes and pathways may improve the understanding of the mechanisms underlying curcumin-induced apoptosis of ACC cells.

Confirmation of DEGs by RT-qPCR and western blotting. The GO and KEGG analysis results showed that the 'MAPK signalling pathway' and 'endoplasmic reticulum' pathway may play notable roles in the curcumin-induced apoptosis of ACC cells. These results were validated using RT-qPCR and western blotting (Fig. 4A-C). HSP70 is a molecular chaperone that inhibits apoptosis (23). After curcumin treatment, HSP70 expression was downregulated, while the expression levels of p-JNK/JNK, p-p38/p38, c-Jun, c-Fos, ATF4 and CHOP increased. These results indicated that the JNK, p38 MAPK and ER stress pathways were activated by curcumin treatment.

CHOP-knockdown inhibits curcumin-induced apoptosis of $S W-13$ cells. To further determine whether CHOP plays a notable role in curcumin-induced apoptosis, a shRNA was used to knock down CHOP expression. As shown in Fig. 5A, CHOP mRNA expression was significantly decreased by $\sim 70 \%$ compared with that in cells transfected with the NC. Following treatment with $40 \mu \mathrm{M}$ curcumin, there was a significant decrease in CHOP mRNA and protein expression compared with the curcumin-treated group (Fig. 5B and C). Moreover, the protein expression levels of the apoptotic factor Bax were decreased, while the protein expression levels of the anti-apoptotic factor Bcl-2 were increased compared with the curcumin-treated group (Fig. 5C).

Curcumin inhibits SW-13 xenograft tumour growth. Based on the inhibitory effects of curcumin on ACC cell proliferation in vitro, a SW-13 xenograft tumour model was established in nude mice. After intraperitoneal injection 


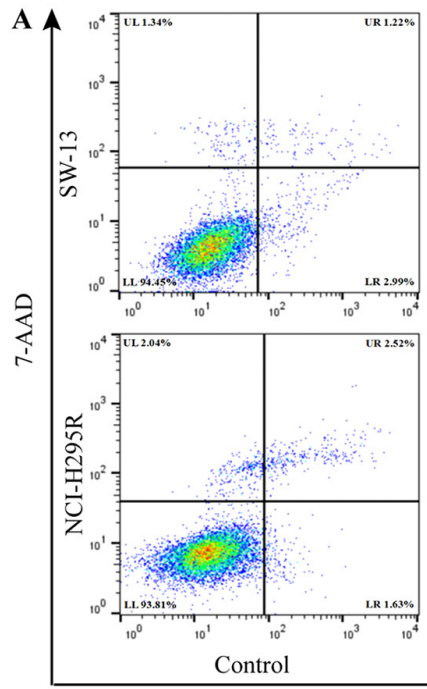

C

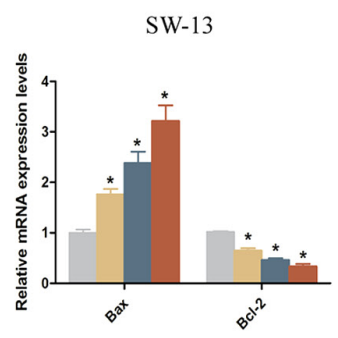

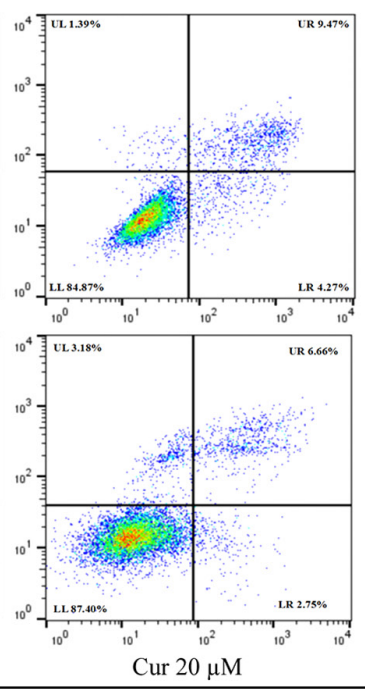
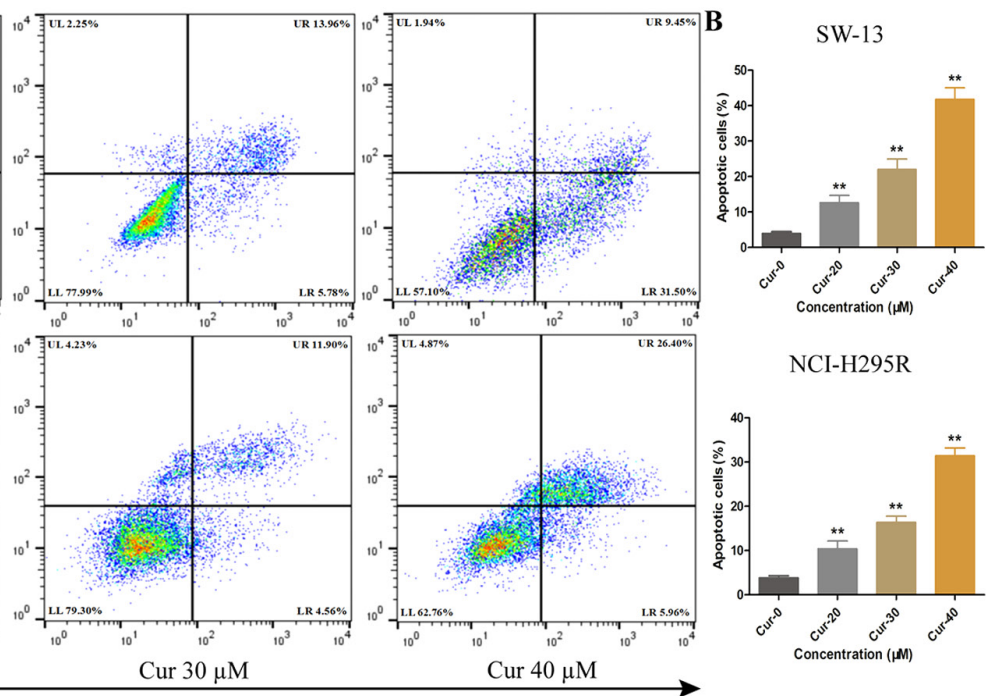

Annexin V-APC

D
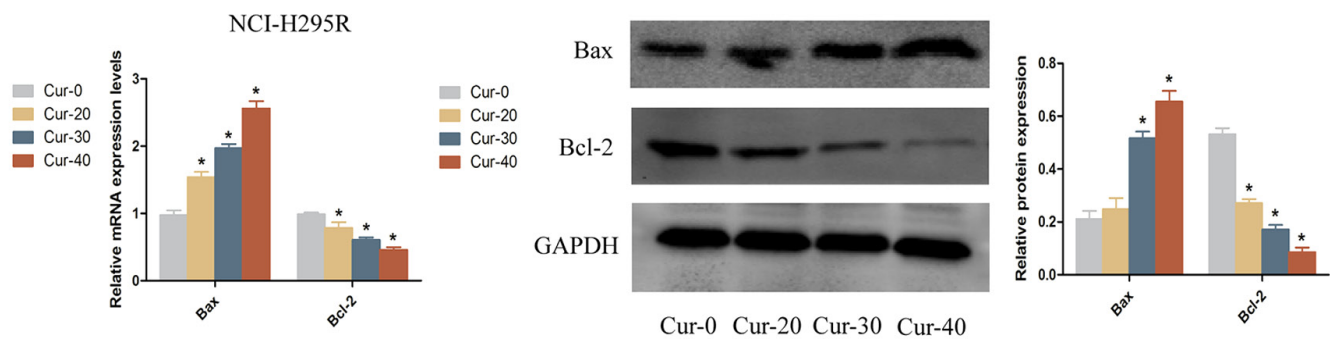

- Cur-0

Cur-20

Cur-30

Cur-0 Cur-20 Cur-30 Cur-40

Figure 2. Curcumin induces the apoptosis of SW-13 and NCI-H295R cells. (A) After curcumin treatment for 24 h, SW-13 and NCI-H295R cells were stained with Annexin V-APC/7-AAD and analysed by flow cytometry. (B) Percentage of apoptotic cells after treatment. (C) mRNA expression levels of Bax and Bcl-2 in SW-13 cells and NCI-H295R cells. (D) Protein expression levels of Bax and Bcl-2 in SW-13 cells. "P<0.05 and *** $\mathrm{P}<0.01$ vs. Cur-0. Cur, curcumin.

of 50 or $100 \mathrm{mg} / \mathrm{kg}$ curcumin or vehicle alone for 2 weeks, a significant decrease in the tumour weight and volume was observed in the groups treated with 50 and $100 \mathrm{mg} / \mathrm{kg}$ curcumin (Fig. 6A-C). As shown in Fig. 6D, the body weights of the mice in the different treatment groups did not change significantly. Curcumin at a dose of $100 \mathrm{mg} / \mathrm{kg}$ exhibited a greater inhibitory effect on tumour growth compared with the other groups, and expansion of the ER was observed under an electron microscope (Fig. 6E). The expression levels of genes in the JNK, p38 MAPK and ER stress pathways were measured in xenograft tumours by RT-qPCR and western blotting, as shown in Fig. 7. After curcumin treatment, HSP70 and Bcl-2 expression was significantly decreased, while Bax expression was significantly increased (Fig. 7A, B and D). The JNK, p38 MAPK and ER stress pathways were activated, and the levels of p-JNK/JNK, p-p38/p38, c-Jun, c-Fos, ATF4 and $\mathrm{CHOP}$ were significantly increased in the 50 and $100 \mathrm{mg} / \mathrm{kg}$ curcumin-treated groups (Fig. 7A-C). These data indicated that curcumin exhibited antitumour activity, was safe to use in vivo and inhibited xenograft tumour growth through the JNK, p38 MAPK and ER stress pathways.

\section{Discussion}

Curcumin is a natural potential anticancer agent with few side effects (24). Curcumin potently inhibits tumour cell apoptosis and has been reported to inhibit the proliferation of human non-small cell lung carcinoma cells (25). In addition, animal studies have shown that curcumin inhibits tumorigenesis and tumour metastasis. Zhu et al (26) reported that curcumin inhibits the proliferation and invasion of monocytic leukaemia cells in vivo. Curcumin was also shown to inhibit the growth and angiogenesis of colorectal cancer CT26 xenografts in nude mice (27) and to decrease tumour growth and augment the cisplatin antitumour effects in Sprague-Dawley rats with 7,12-dimethyl benz[a]anthracene-induced breast cancer (28). ACC is malignant and aggressive; therefore, the majority of patients who relapse or who have metastatic disease do not survive (29). The present study used two ACC cell lines to demonstrate that curcumin inhibits the viability, migration and invasion, and induces apoptosis in ACC cells in vitro. Moreover, curcumin was well tolerated and effectively inhibited tumour growth in vivo in a nude mouse xenograft model. However, since it has low bioavailability, its derivative curcumin liposomes should be used to enhance solubility in future studies.

Curcumin can inhibit cancer by exerting several biological effects, including decreasing proliferation, inducing apoptosis, inhibiting invasion and regulating the cell cycle (30-32). Curcumin increases glioblastoma cell death by inhibiting the PI3K/Akt/mTOR signaling pathway (33). In addition, curcumin inhibits bladder cancer cell proliferation and bladder tumour growth by decreasing Sp1, Sp3 and Sp4 protein levels (34). However, curcumin exerts an antitumour effect by inducing apoptosis in gastric and lung cancer cells by activation of Bax, caspases and pro-apoptotic ER stress $(35,36)$. 
A

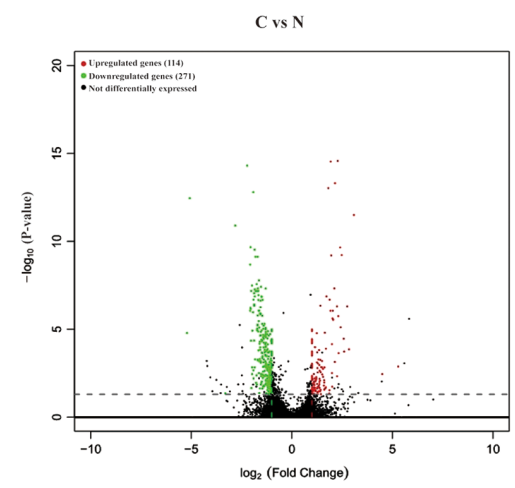

C

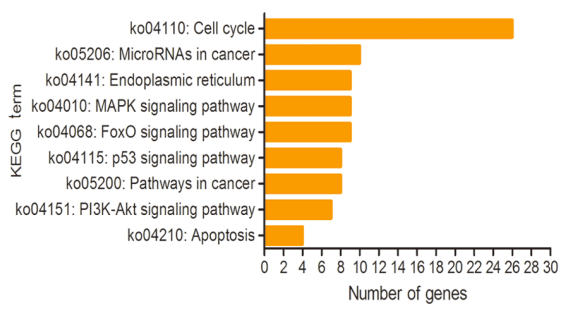

B

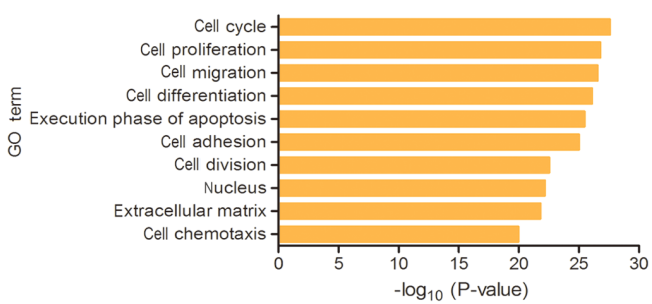

D

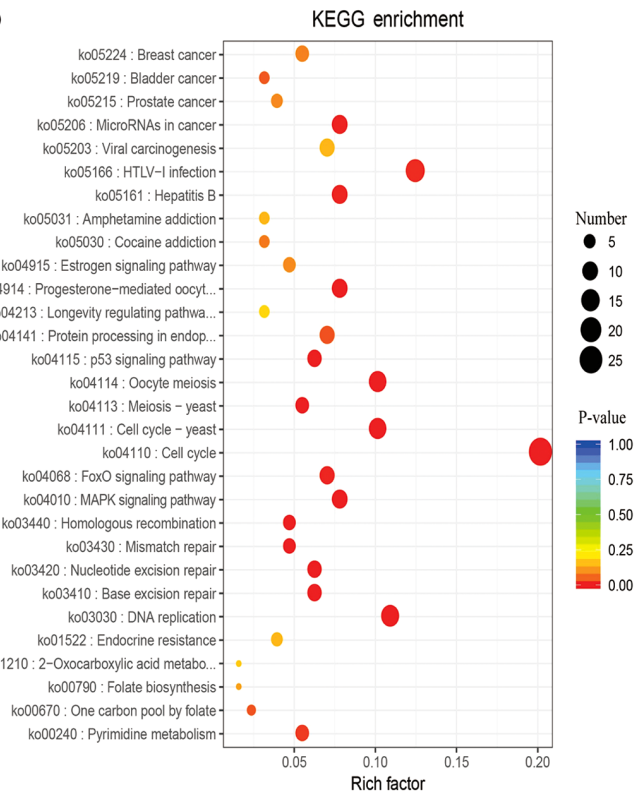

Figure 3. RNA sequencing and bioinformatic analyses of the mechanism of curcumin in ACC. (A) Volcano plot of differentially expressed genes in the control and curcumin-treated groups. (B) The top ten enriched GO terms. (C) KEGG pathway analysis of curcumin-induced apoptosis in ACC cells. (D) KEGG enrichment analysis. The changes in the size and colour of the nodes denote the enrichment scores. KEGG, Kyoto Encyclopedia of Genes and Genomes; $\mathrm{N}$, control group; $\mathrm{C}$, curcumin-treated group; ACC, adrenocortical carcinoma.

A

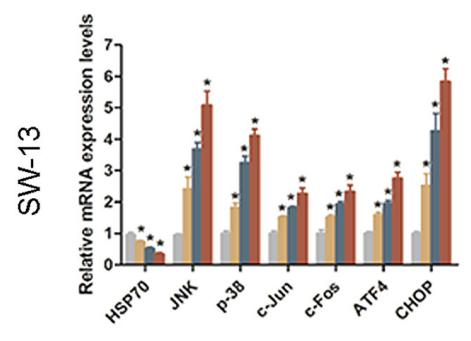

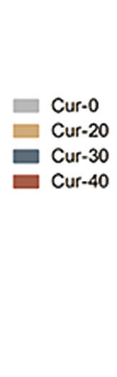

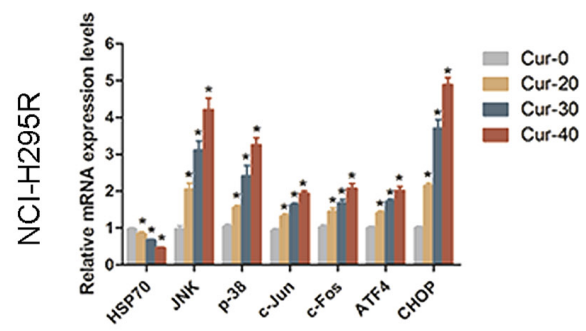

B

HSP70

c-Jun

c-Fos

ATF4

CHOP

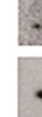

GAPDH
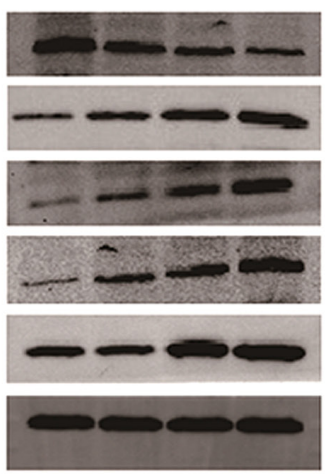

Cur-0 Cur-20 Cur-30 Cur-40

C

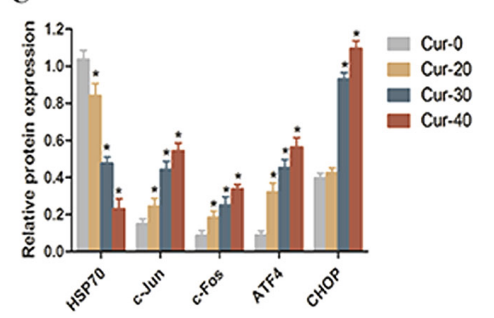

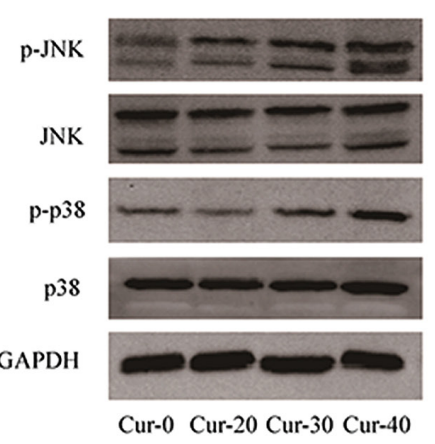

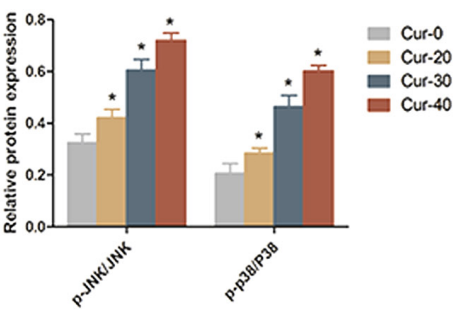

Figure 4. Curcumin induces apoptosis of adrenocortical carcinoma cells through the JNK, p38 MAPK and endoplasmic reticulum stress pathways. (A) mRNA expression levels of HSP70, JNK, p38, c-Jun, c-Fos, ATF4 and CHOP in SW-13 cells and NCI-H295R cells treated with 0, 20,30 or 40 $\mu$ M curcumin. (B) Protein expression levels in SW-13 cells were analysed by western blotting. (C) Quantification of the western blotting results. "P<0.05 vs. Cur- 0 . HSP70, heat shock protein 70; ATF4, activating transcription factor 4; CHOP, C/EBP homologous protein; p, phosphorylated. 
A

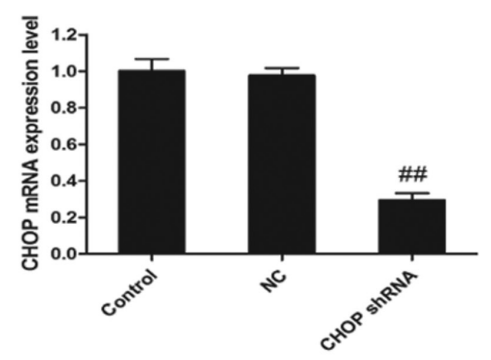

C

CHOP

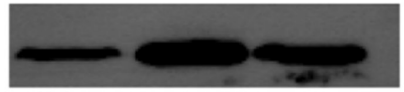

GAPDH

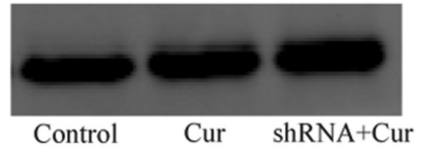

Bax

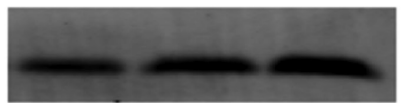

Bcl-2

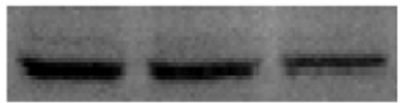

GAPDH

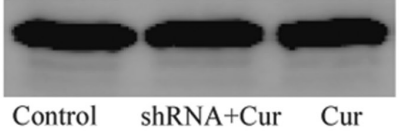

B
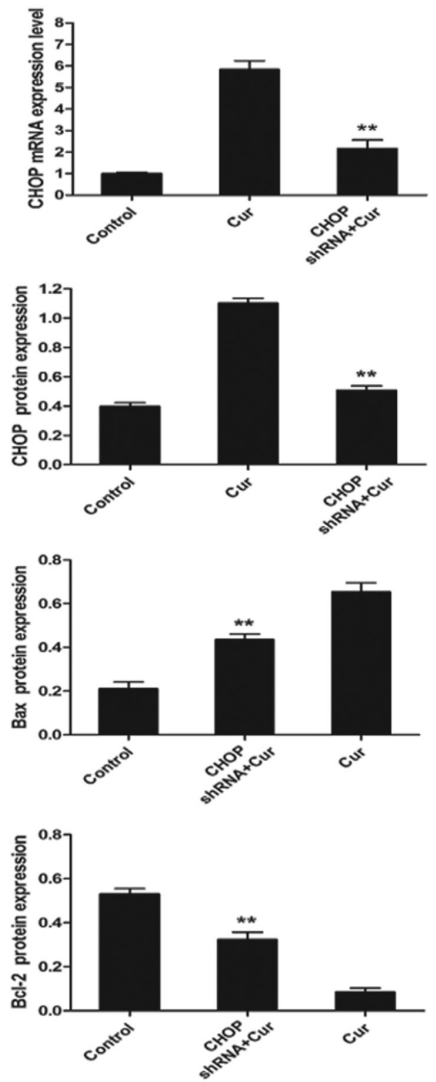

Figure 5. CHOP-knockdown inhibits curcumin-induced apoptosis of SW-13 cells. (A) CHOP mRNA expression was evaluated after CHOP-knockdown. ${ }^{\# \prime} \mathrm{P}<0.01$ vs. NC. (B) CHOP mRNA expression was evaluated after $40 \mu \mathrm{M}$ curcumin treatment. (C) Protein expression levels of CHOP, Bax and Bcl-2 after $40 \mu \mathrm{M}$ curcumin treatment. ${ }^{* *} \mathrm{P}<0.01$ vs. Cur. CHOP, C/EBP homologous protein; shRNA, short hairpin RNA; Cur, curcumin; NC, negative control.
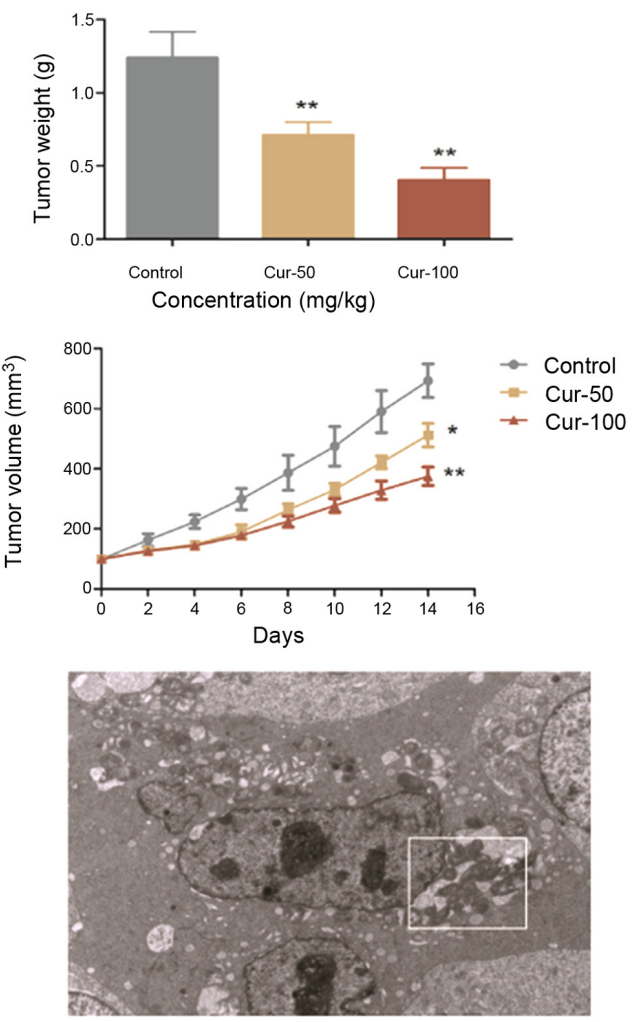

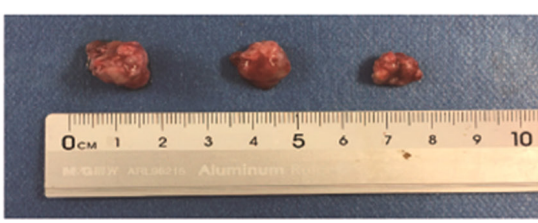

Control Cur-50 Cur-100

D
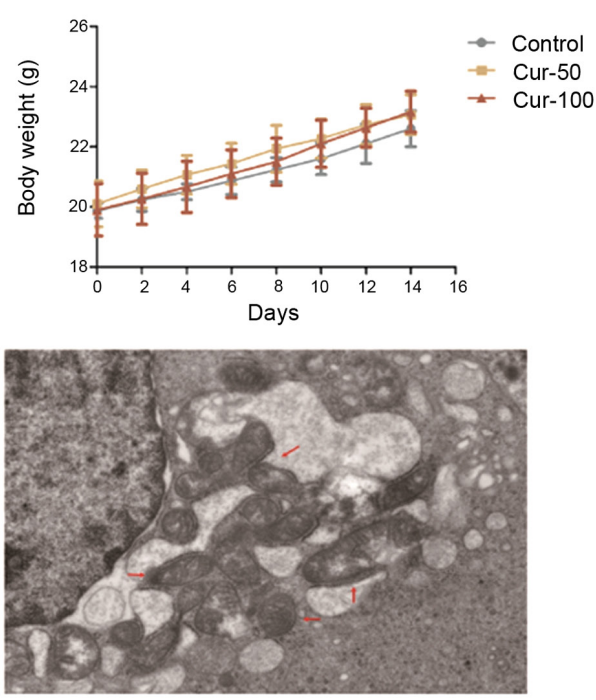

Figure 6. Curcumin inhibits SW-13 xenograft tumour growth in vivo. (A) Tumour weights of mice in the experimental groups. (B) SW-13 xenograft tumours. (C) Tumour volumes at 0,2, 4, 6, 8, 10, 12 and 14 days. (D) Changes in the body weight of mice in the different groups. (E) ER morphology was examined with an electron microscope and revealed ER expansion (red arrows) in xenograft tumours treated with curcumin. Original magnification, $\mathrm{x} 2,500$ and $\mathrm{x} 7,000$. ${ }^{*} \mathrm{P}<0.05$ and ${ }^{* *} \mathrm{P}<0.01$ vs. control. ER, endoplasmic reticulum; Cur, curcumin. 


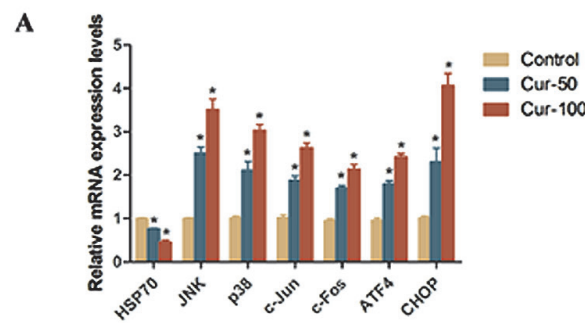

C
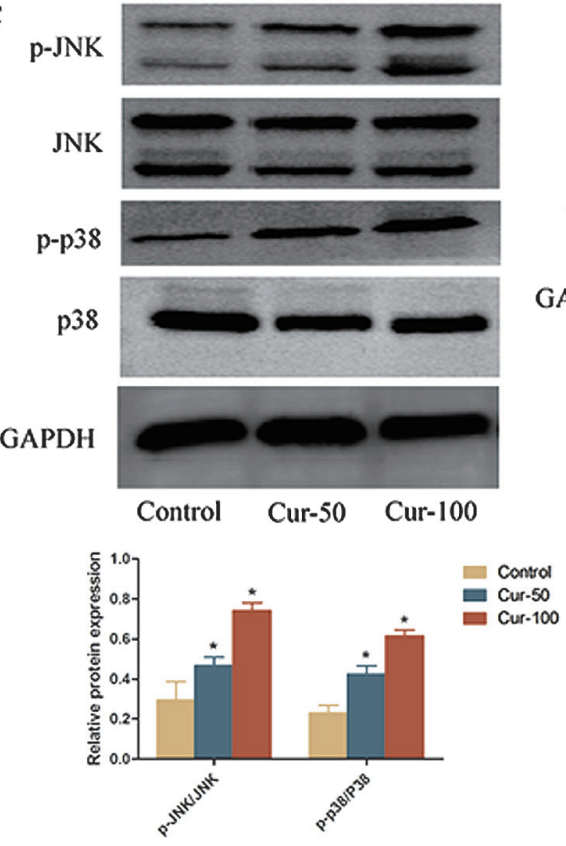

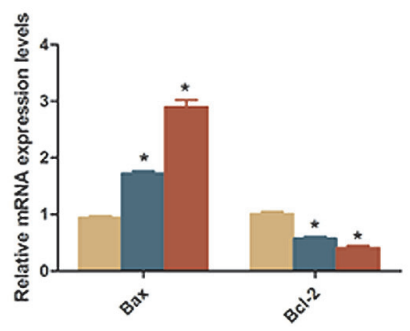

D
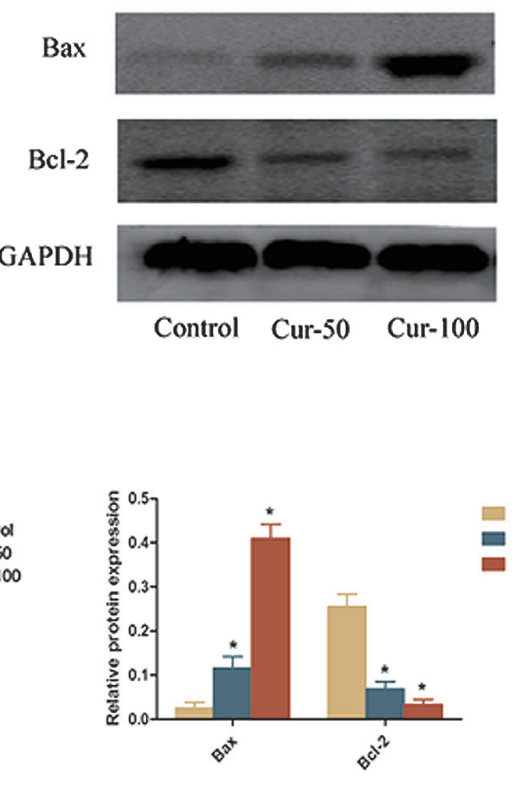

B
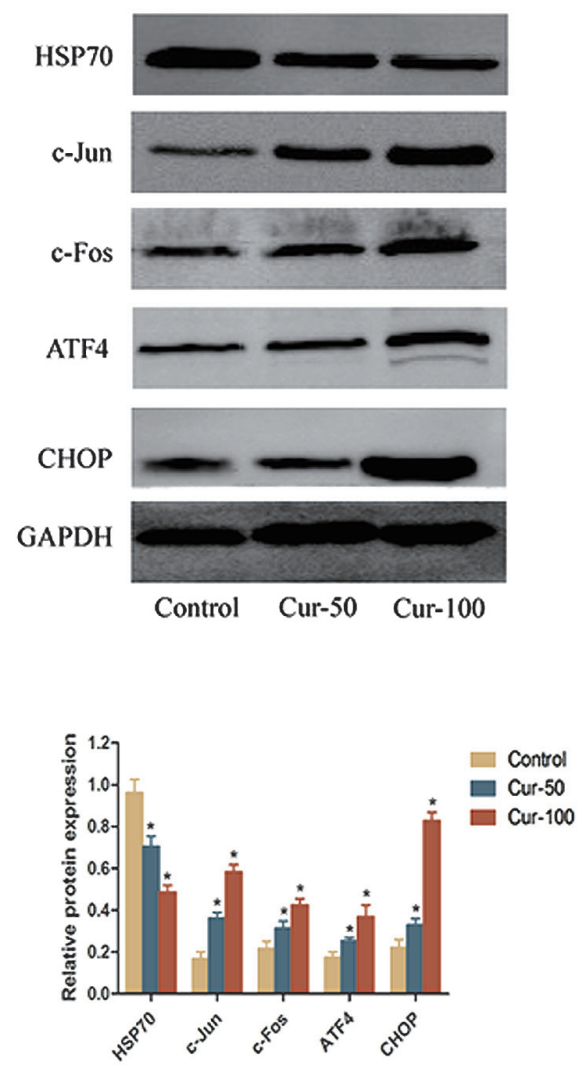

Figure 7. Expression levels of differentially expressed genes in the JNK, p38 MAPK and endoplasmic reticulum stress pathways in xenograft tumours treated with 50 or $100 \mathrm{mg} / \mathrm{kg}$ curcumin. (A) mRNA expression levels of HSP70, JNK, p38, c-Jun, c-Fos, ATF4, CHOP, Bax and Bcl-2 in xenograft tumours. (B) Protein expression levels of HSP70, c-Jun, c-Fos, ATF4, and CHOP in xenograft tumours. (C) Protein expression levels of p-JNK/JNK and p-p38/p38 in xenograft tumours. (D) Protein expression levels of Bax and Bcl-2 in xenograft tumours. "P $<0.05$ vs. control. HSP70, heat shock protein 70; ATF4, activating transcription factor 4; CHOP, C/EBP homologous protein; p, phosphorylated; Cur, curcumin.

In the present study, transcriptomic analysis was performed in ACC cells to explore potential target genes and signalling mechanisms active after curcumin treatment. Hub genes and signalling pathways that may serve important roles in the curcumin-induced apoptosis of ACC cells were identified. A total of 385 DEGs, 114 upregulated and 271 downregulated, were identified. GO and KEGG pathway enrichment analyses showed that the 'cell cycle', 'microRNAs in cancer', 'MAPK signaling pathway' and 'endoplasmic reticulum' were the predominant pathways associated with curcumin-induced apoptosis of ACC cells.

HSP70 is a molecular chaperone required for the regulation of cellular homeostasis via the control of protein folding, translocation, biogenesis and degradation (37). HSP70, a member of the HSP family, has been reported to be highly expressed in numerous types of cancer and is associated with higher tumour grade, metastasis, chemotherapeutic resistance and poor prognosis $(38,39)$. Nuclear translocation and expression of the HSP70 protein is correlated with the stage and the prognosis of patients with papillary thyroid cancer (40). The overall survival rates of patients with nasopharyngeal carcinoma with positive expression of HSP70 were significantly lower than those with negative expression (41). Sheng et al (42) showed that inhibition of HSP70 expression enhances the sensitivity of gastric cancer cells to cisplatin via the MAPK signalling pathway and that HSP70 may be a therapeutic target in gastric cancer. The present study suggested that the MAPK signalling pathway was involved in the curcumin-induced apoptosis of ACC cells. JNK and p38 are essential components of the MAPK signal transduction pathway, leading to programmed cell death in response to certain stimuli $(43,44)$. The present results indicated that as curcumin concentration increased, HSP70 expression decreased, and JNK and p38 were activated and phosphorylated. JNK and p38 are typically described as stress-activated kinases that mediate apoptotic signals (45). HSP70 senses the accumulation of abnormal proteins after heat shock and other stresses to regulate JNK and p38 (46). Furthermore, JNK and p38 orchestrate cellular responses by mediating their downstream transcription factor activator protein-1, a c-Jun/c-Fos heterodimer. JNK and p38 are activated to modify the expression of CHOP, and participate in apoptosis induced by the ER stress pathway $(47,48)$.

Curcumin has been reported to increase the expression of ATF4 and CHOP, which are considered the hallmarks of ER stress-induced apoptosis $(49,50)$. During severe or prolonged ER stress, ATF4 is activated and binds to AARE1 on the CHOP promoter, further promoting the expression 
of the ER stress-associated apoptotic factor CHOP (51-53). After curcumin treatment, the expression levels of ATF4, and $\mathrm{CHOP}$ increased in ACC cells in vitro and in vivo. The current study investigated the role of $\mathrm{CHOP}$ in curcumin-induced apoptosis using lentivirus transfection. The shRNA-mediated knockdown of CHOP expression inhibited curcumin-induced apoptosis in ACC SW-13 cells. The current results are consistent with those of previous studies (54-56). Therefore, activation of JNK and p38 to stimulate ER stress appears to be a major contributor to the curcumin-induced apoptosis of ACC cells.

In conclusion, curcumin inhibited ACC growth and induced apoptosis. Curcumin activated JNK and p38 MAPK, and stimulated ER stress, which may serve a notable role in apoptosis. Thus, the present results may facilitate the search for novel treatments of ACC and for understanding the molecular mechanisms underlying the effects of curcumin. Curcumin may be a promising candidate for ACC therapy. Nonetheless, future studies should investigate the mechanism of the cell cycle and microRNA pathways in curcumin-induced apoptosis of ACC cells in curcumin liposome experiments.

\section{Acknowledgements}

Not applicable.

\section{Funding}

The present study was supported by The National Natural Science Foundation of China (grant nos. 81060220, 81860146 and 81660138), The Ministry of Science and Technology (grant nos. 2016YFC0901200 and 2016YFC0901205), The Nanning Scientific Research and Technology Development Plan Project (grant no. zc20203009) and The Guangxi Medical and Health Self-financing Project (grant no. Z20200122).

\section{Availability of data and materials}

The datasets generated and/or analyzed during the current study are available in the [SRA] repository, [http://www.ncbi. nlm.nih.gov/bioproject/699600].

\section{Authors' contributions}

XH, DL, YM and ZL conceived and designed the study. XH, CL, HY, XL, XD, XHL, LL, ZH, DL and ZL conducted the study and analysed the data. XH and ZL confirmed the authenticity of all the raw data. XH drafted the initial manuscript. DL, YM and ZL guided the writing. All authors have read and approved the final manuscript.

\section{Ethics approval and consent to participate}

The in vivo animal experiments were approved by The Animal Ethics and Welfare Committee of Guangxi Medical University (Nanning, China; approval no. 201903022).

\section{Patient consent for publication}

Not applicable.

\section{Competing interests}

The authors declare that they have no competing interests.

\section{References}

1. Roca E, Berruti A, Sbiera S, Rapa I, Oneda E, Sperone P, Ronchi CL,FerrariL, GrisantiS, Germano A, et al: Topoisomerase $2 \alpha$ and thymidylate synthase expression in adrenocortical cancer. Endocr Relat Cancer 24: 319-327, 2017.

2. Simon G, Pattou F, Mirallié E, Lifante JC, Nominé C, Arnault V, de Calan L, Caillard C, Carnaille B, Brunaud L, et al: Surgery for recurrent adrenocortical carcinoma: A multicenter retrospective study. Surgery 161: 249-256, 2017.

3. Assié G, Antoni G, Tissier F, Caillou B, Abiven G, Gicquel C, Leboulleux S, Travagli JP, Dromain C, Bertagna X, et al: Prognostic parameters of metastatic adrenocortical carcinoma. J Clin Endocrinol Metab 92: 148-154, 2007.

4. Ruggiero C, Doghman-Bouguerra M, Ronco C, Benhida R, Rocchi S and Lalli E: The GRP78/BiP inhibitor HA15 synergizes with mitotane action against adrenocortical carcinoma cells through convergent activation of ER stress pathways. Mol Cell Endocrinol 474: 57-64, 2018.

5. Hermsen IG, Haak HR, de Krijger RR, Kerkhofs TM, Feelders RA, de Herder WW, Wilmink H, Smit JW, Gelderblom H, de Miranda NF, et al: Mutational analyses of epidermal growth factor receptor and downstream pathways in adrenocortical carcinoma. Eur J Endocrinol 169: 51-58, 2013.

6. Baudin E, Pellegriti G, Bonnay M, Penfornis A, Laplanche A, Vassal $\mathrm{G}$ and Schlumberger M: Impact of monitoring plasma 1,1-dichlorodiphenildichloroethane (o,p'DDD) levels on the treatment of patients with adrenocortical carcinoma. Cancer 92: 1385-1392, 2001

7. Muratori L, Pia A, Reimondo G, Pisano C, La Salvia A, Puglisi S, Scagliotti GV and Sperone P: Prolonged adrenal insufficiency after the discontinuation of mitotane therapy. Endocr Metab Immune Disord Drug Targets 20: 485-487, 2020.

8. Else T, Kim AC, Sabolch A, Raymond VM, Kandathil A, Caoili EM, Jolly S, Miller BS, Giordano TJ and Hammer GD: Adrenocortical carcinoma. Endocr Rev 35: 282-326, 2014.

9. SeidelE, Walenda G, Messerschmidt C, Obermayer B, Peitzsch M, Wallace P, Bahethi R, Yoo T, Choi M, Schrade P, et al: Generation and characterization of a mitotane-resistant adrenocortical cell line. Endocr Connect 9: 122-134, 2020.

10. Schaffer M, Schaffer PM and Bar-Sela G: An update on Curcuma as a functional food in the control of cancer and inflammation. Curr Opin Clin Nutr Metab Care 18: 605-611, 2015.

11. Sun C, Zhang S, Liu C and Liu X: Curcumin Promoted miR-34a expression and suppressed proliferation of gastric cancer cells. Cancer Biother Radiopharm 34: 634-641, 2019.

12. Milacic V, Banerjee S, Landis-Piwowar KR, Sarkar FH, Majumdar AP and Dou QP: Curcumin inhibits the proteasome activity in human colon cancer cells in vitro and in vivo. Cancer Res 68: 7283-7292, 2008.

13. Somasundaram S, Edmund NA, Moore DT, Small GW, Shi YY and Orlowski RZ: Dietary curcumin inhibits chemotherapy-induced apoptosis in models of human breast cancer. Cancer Res 62: 3868-3875, 2002.

14. Sreekanth CN, Bava SV, Sreekumar E and Anto RJ: Molecular evidences for the chemosensitizing efficacy of liposomal curcumin in paclitaxel chemotherapy in mouse models of cervical cancer. Oncogene 30: 3139-3152, 2011.

15. Watson JL, Hill R, Yaffe PB, Greenshields A, Walsh M, Lee PW, Giacomantonio CA and Hoskin DW: Curcumin causes superoxide anion production and p53-independent apoptosis in human colon cancer cells. Cancer Lett 297: 1-8, 2010.

16. Killian PH, Kronski E, Michalik KM, Barbieri O, Astigiano S, Sommerhoff CP, Pfeffer U, Nerlich AG and Bachmeier BE: Curcumin inhibits prostate cancer metastasis in vivo by targeting the inflammatory cytokines CXCL1 and -2 . Carcinogenesis 33: 2507-2519, 2012.

17. Wang Y, Xiao J, Zhou H, Yang S, Wu X, Jiang C, Zhao Y, Liang D, Li X and Liang G: A novel monocarbonyl analogue of curcumin, (1E,4E)-1,5-bis(2,3-dimethoxyphenyl)penta-1,4-dien-3-one, induced cancer cell $\mathrm{H} 460$ apoptosis via activation of endoplasmic reticulum stress signaling pathway. J Med Chem 54: 3768-3778, 2011. 
18. Khan AQ,AhmedEI,Elareer N,Fathima H,Prabhu KS, Siveen KS Kulinski M, Azizi F, Dermime S, et al: Curcumin-mediated apoptotic cell death in papillary thyroid cancer and cancer stem-like cells through targeting of the JAK/STAT3 signaling pathway. International journal of molecular sciences 212020.

19. Sharma RA, McLelland HR, Hill KA, Ireson CR, Euden SA, Manson MM, Pirmohamed M, Marnett LJ, Gescher AJ, et al: Pharmacodynamic and pharmacokinetic study of oral Curcuma extract in patients with colorectal cancer. Clin Cancer Res 7: 1894-1900, 2001.

20. Saghatelyan T, Tananyan A, Janoyan N, Tadevosyan A, Petrosyan H, Hovhannisyan A, Hayrapetyan L, Arustamyan M, Arnhold J, et al: Efficacy and safety of curcumin in combination with paclitaxel in patients with advanced, metastatic breast cancer: A comparative, randomized, double-blind, placebo-controlled clinical trial. Phytomedicine 70: 153218, 2020.

21. Choi YH, Han DH, Kim SW, Kim MJ, Sung HH, Jeon HG, Jeong BC, Seo SI, Jeon SS, Lee HM, et al: A randomized, double-blind, placebo-controlled trial to evaluate the role of curcumin in prostate cancer patients with intermittent androgen deprivation. Prostate 79: 614-621, 2019.

22. Livak KJ and Schmittgen TD: Analysis of relative gene expression data using real-time quantitative PCR and the 2(-Delta Delta C(T)) method. Methods 25: 402-408, 2001.

23. Boudesco C, Cause S, Jego G and Garrido C: Hsp70: A cancer target inside and outside the cell. Methods Mol Biol 1709: 371-396, 2018.

24. Lee WH, Loo CY, Young PM, Traini D, Mason RS and Rohanizadeh R: Recent advances in curcumin nanoformulation for cancer therapy. Expert Opin Drug Deliv 11: 1183-1201, 2014.

25. Shishodia S, Potdar P, Gairola CG and Aggarwal BB: Curcumin (diferuloylmethane) down-regulates cigarette smoke-induced NF-kappaB activation through inhibition of IkappaBalpha kinase in human lung epithelial cells: Correlation with suppression of COX-2, MMP-9 and cyclin D1. Carcinogenesis 24: 1269-1279, 2003.

26. Zhu G, Shen Q, Jiang H, Ji O, Zhu L and Zhang L: Curcumin inhibited the growth and invasion of human monocytic leukaemia SHI-1 cells in vivo by altering MAPK and MMP signalling. Pharm Biol 58: 25-34, 2020.

27. Moradi-Marjaneh R, Hassanian SM, Rahmani F, AghaeeBakhtiari SH, Avan A and Khazaei M: Phytosomal curcumin elicits anti-tumor properties through suppression of angiogenesis, cell proliferation and induction of oxidative stress in colorecta cancer. Curr Pharm Des 24: 4626-4638, 2018.

28. Kumar P, Barua CC, Sulakhiya K and Sharma RK: Curcumin ameliorates cisplatin-induced nephrotoxicity and potentiates its anticancer activity in sd rats: Potential role of curcumin in breast cancer chemotherapy. Front Pharmacol 8: 132, 2017.

29. Kerkhofs TM, Ettaieb MH, Hermsen IG and Haak HR: Developing treatment for adrenocortical carcinoma. Endocr Relat Cancer 22: R325-R338, 2015.

30. Chen L, Zhan CZ, Wang T, You H and Yao R: Curcumin inhibits the proliferation, migration, invasion, and apoptosis of diffuse large B-cell lymphoma cell line by regulating MiR-21/VHL axis. Yonsei Med J 61: 20-29, 2020.

31. Hassanalilou T, Ghavamzadeh S and Khalili L: Curcumin and gastric cancer: A review on mechanisms of action. J Gastrointest Cancer 50: 185-192, 2019.

32. He YC, He L, Khoshaba R, Lu FG, Cai C, Zhou FL, Liao DF and Cao D: Curcumin nicotinate selectively induces cancer cell apoptosis and cycle arrest through a P53-mediated mechanism. Molecules 24: 4179, 2019.

33. Maiti P, Plemmons A and Dunbar GL: Combination treatment of berberine and solid lipid curcumin particles increased cell death and inhibited PI3K/Akt/mTOR pathway of human cultured glioblastoma cells more effectively than did individual treatments. PLoS One 14: e0225660, 2019.

34. Chadalapaka G, Jutooru I, Chintharlapalli S, Papineni S, Smith R III, Li X and Safe S: Curcumin decreases specificity protein expression in bladder cancer cells. Cancer Res 68: 5345-5354, 2008.

35. Firouzi Amoodizaj F, Baghaeifar S, Taheri E, Farhoudi Sefidan Jadid M, Safi M, Seyyed Sani N, Hajazimian S, Isazadeh A and Shanehbandi D: Enhanced anticancer potency of doxorubicin in combination with curcumin in gastric adenocarcinoma. J Biochem Mol Toxicol 34: e22486, 2020.

36. Lin SS, Huang HP, Yang JS, Wu JY, Hsia TC, Lin CC, Lin CW, Kuo CL, Gibson Wood W and Chung JG: DNA damage and endoplasmic reticulum stress mediated curcumin-induced cell cycle arrest and apoptosis in human lung carcinoma A-549 cells through the activation caspases cascade- and mitochondrial-dependent pathway. Cancer Lett 272: 77-90, 2008.
37. Das JK, Xiong X, Ren X, Yang JM and Song J: Heat Shock Proteins in Cancer Immunotherapy. J Oncol 2019: 3267207, 2019.

38. Kumar S, Stokes J III, Singh UP, Scissum Gunn K, Acharya A, Manne U and Mishra M: Targeting Hsp70: A possible therapy for cancer. Cancer Lett 374: 156-166, 2016.

39. Yun CW, Kim HJ, Lim JH and Lee SH: Heat shock proteins: agents of cancer development and therapeutic targets in anti-cancer therapy. Cells 9: 60, 2019.

40. Avdalyan AM, Ivanov AA, Lushnikova EL, Molodykh OP and Vikhlyanov IV: The relationship of immunoexpression of Ki-67 and Hsp70 with clinical and norphological parameters and prognosis of papillary thyroid cancer. Bull Exp Biol Med 168: 688-693, 2020

41. Feng J,Zhan Y, Zhang Y, Zheng H, Wang W and Fan S: Increased expression of heat shock protein (HSP) 10 and HSP70 correlates with poor prognosis of nasopharyngeal carcinoma. Cancer Manag Res 11: 8219-8227, 2019.

42. Sheng L, Tang T, Liu Y, Ma Y, Wang Z, Tao H, Zhang Y and Qi Z Inducible HSP70 antagonizes cisplatin induced cell apoptosis through inhibition of the MAPK signaling pathway in HGC 27 cells. Int J Mol Med 42: 2089-2097, 2018.

43. Wagner EF and Nebreda AR: Signal integration by JNK and p38 MAPK pathways in cancer development. Nat Rev Cancer 9: 537-549, 2009

44. Yue J and Lopez JM: Understanding MAPK signaling pathways in apoptosis. Int J Mol Sci 21: 2346, 212020.

45. Sui X, Kong N, Ye L, Han W, Zhou J, Zhang Q, He C and Pan H: p38 and JNK MAPK pathways control the balance of apoptosis and autophagy in response to chemotherapeutic agents. Cancer Lett 344: 174-179, 2014

46. Gabai VL, Meriin AB, Mosser DD, Caron AW, Rits S, Shifrin VI and Sherman MY: Hsp70 prevents activation of stress kinases. A novel pathway of cellular thermotolerance. J Biol Chem 272 18033-18037, 1997

47. Zheng QY, Li PP, Jin FS, Yao C, Zhang GH, Zang T and Ai X: Ursolic acid induces ER stress response to activate ASK1-JNK signaling and induce apoptosis in human bladder cancer T24 cells. Cell Signal 25: 206-213, 2013.

48. Choi JH, Jeong YJ, Yu AR, Yoon KS, Choe W, Ha J, Kim SS, Yeo EJ and Kang I: Fluoxetine induces apoptosis through endoplasmic reticulum stress via mitogen-activated protein kinase activation and histone hyperacetylation in SK-N-BE(2)-M17 human neuroblastoma cells. Apoptosis 22: 1079-1097, 2017.

49. Mathur A, Abd Elmageed ZY, Liu X, Kostochka ML, Zhang H, Abdel-Mageed AB and Mondal D: Subverting ER-stress towards apoptosis by nelfinavir and curcumin coexposure augments docetaxel efficacy in castration resistant prostate cancer cells. PLoS One 9: e103109, 2014.

50. Zinszner H, Kuroda M, Wang X, Batchvarova N, Lightfoot RT, Remotti H, Stevens JL and Ron D: CHOP is implicated in programmed cell death in response to impaired function of the endoplasmic reticulum. Genes Dev 12: 982-995, 1998.

51. Liu TH, Tu WQ, Tao WC, Liang QE, Xiao Y and Chen LG: Verification of resveratrol inhibits intestinal aging by downregulating ATF4/Chop/Bcl-2/Bax signaling pathway: Based on network pharmacology and animal experiment. Front Pharmacol 11: 1064, 2020.

52. Wang X, Zhuang Y, Fang Y, Cao H, Zhang C, Xing C, Guo X, Li G, Liu P, Hu G, et al: Endoplasmic reticulum stress aggravates copper-induced apoptosis via the PERK/ATF4/CHOP signaling pathway in duck renal tubular epithelial cells. Environ Pollut 272: 115981,2021

53. Khatun H, Wada Y, Konno T, Tatemoto H and Yamanaka KI Endoplasmic reticulum stress attenuation promotes bovine oocyte maturation in vitro. Reproduction 159: 361-370, 2020.

54. Liang T, Zhang X, Xue W, Zhao S, Zhang X and Pei J: Curcumin induced human gastric cancer BGC-823 cells apoptosis by ROS-mediated ASK1-MKK4-JNK stress signaling pathway. Int J Mol Sci 15: 15754-15765, 2014.

55. Yu X, Zhong J, Yan L, Li J, Wang H, Wen Y and Zhao Y: Curcumin exerts antitumor effects in retinoblastoma cells by regulating the JNK and p38 MAPK pathways. Int J Mol Med 38: 861-868, 2016.

56. Zhang W, Chen L, Shen Y and Xu J: Rifampicin-induced injury in L02 cells is alleviated by 4-PBA via inhibition of the PERK-ATF4-CHOP pathway. Toxicol In Vitro 36: 186-196, 2016.

This work is licensed under a Creative Commons Attribution-NonCommercial-NoDerivatives 4.0 International (CC BY-NC-ND 4.0) License. 